\section{Congenital hypertrophic pyloric stenosis in triplets}

The development of congenital hypertrophic pyloric stenosis concurrently in both sibs of uniovular, as well as binovular, twin pregnancies is well documented and has been the subject of numerous reviews (Metrakos, 1953; MacMahon and McKeown, 1955). The condition has also been described in 3 (Cameron, 1955), 4 (Gailey, 1948), and even 5 sibs (Benson, 1970) in the same family.

This is the first report of the simultaneous occurrence of congenital hypertrophic pyloric stenosis in all the sibs of a triplet pregnancy.

\section{Case report}

The triplet boys were born on 1 March 1973, after a pregnancy complicated in the first trimester by hyperemesis gravidarum and a progesterone deficiency necessitating replacement therapy. The first 2 infants were vertex deliveries with forceps assistance, and the third was a breech delivery. Birthweights were 2700, 2500 , and $2000 \mathrm{~g}$, respectively.

The first-born infant was admitted to hospital on 25 March 1973, with a 6-day history of projectile vomiting. There was mild dehydration and visible gastric peristalsis, and a palpable pyloric 'tumour' in the right hypochondrium was present. Pyloromyotomy was performed on the day after admission.

The second- and third-born triplets were admitted to hospital on 28 March 1973, with projectile vomiting of 6 and 1 day's duration, respectively. Palpable pyloric masses were found in both cases. There was no dehydration. Pyloromyotomies were performed on both infants.

Blood grouping showed the first 2 infants to be group $O C D E$ cde $M N$, and the third to be group $O C D E$ cde MM.

\section{Comment}

Although the aetiology of congenital hypertrophic pyloric stenosis is still subject to speculation, both genetic and environmental factors have been implicated. The facts which tend to substantiate a genetic predisposition include an increased incidence in the children of affected parents (Carter, 1961), a definite male predominance, and a higher incidence of concordance in monozygotic $(66 \cdot 7 \%)$ as opposed to dizygotic twins $(3.49 \%$ ) (Metrakos, 1953).

The nature of the environmental factors concerned has not been accurately defined, but the 'skill' with which the infant is handled may be of importance (Benson, 1970). The time of onset of symptoms is related to the length of extrauterine life, the frequency of feeding (Gerrard, Waterhouse, and
Maurice, 1955), and the birth rank of the infant (McKeown, MacMahon, and Record, 1952).

Carter (1961) has suggested that there is a single main 'dominant' gene and a multifactorial background which together provide the genotype underlying predisposition to pyloric stenosis. The occurrence of pyloric stenosis in all 3 infants of a nonidentical triplet pregnancy (see blood groupings) tends to substantiate the latter hypothesis.

\section{Summary}

Pyloric stenosis affected all 3 of male triplets.

\section{REFERENCES}

Benson, C. D. (1970). Infantile pyloric stenosis. In Progress in Pediatric Surgery, Vol. 1, p. 63. Ed. by P. P. Rickham, W. C. Hecker, and J. Prévot. Urban and Schwarzenberg, Munich.

Cameron, A. L. (1955). Familial occurrence of congenital hypertrophic pyloric stenosis. Report of cases in siblings and a cousin and review of the literature. Archives of Surgery, 70, 877.

Carter, C. O. (1961). Genetic factors in pyloric stenosis. Proceedings of the Royal Society of Medicine, 54, 453.

Gailey, A. A. H. (1948). Congenital hypertrophic pyloric stenosis: report of four cases in brothers. British Medical fournal, 1, 100.

Gerrard, J. W., Waterhouse, J. A. H., and Maurice, D. G. (1955). Infantile pyloric stenosis. Archives of Disease in Childhood, 30, 493.

McKeown, T., MacMahon, B., and Record, R. G. (1952). Evidence of post-natal environmental influence in the aetiology of infantile pyloric stenosis. Archives of Disease in Childhood, 27, 386.

MacMahon, B., and McKeown, T. (1955). Infantile hypertrophic pyloric stenosis: data on 81 pairs of twins. Acta Geneticae Medicae et Gemellologiae, 4, 320.

Metrakos, J. D. (1953). Congenital hypertrophic pyloric stenosis in twins. Archives of Disease in Childhood, 28, 351.

\section{LEWIS SPITZ*}

Department of Paediatric Surgery, Transvaal Memorial Hospital for Children and University of Witwatersrand, Johannesburg, South Africa.

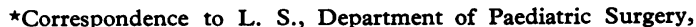
Transvaal Memorial Hospital for Children, Joubert Street Extension, Milner Park, Johannesburg, South Africa.

\section{Mixed pneumococcal and tuberculous meningitis}

Mixed bacterial meningitis is rare and occurs most frequently in young infants (Herweg, Middelkamp, and Hartmann, 1963). This case report of meningitis due to two organisms, Streptococcus pneumoniae and Mycobacterium tuberculosis, shows some of the diagnostic difficulties encountered and the importance of considering the possibility of a mixed infection. 


\section{Case report}

A girl was born by normal delivery, weighing $1.9 \mathrm{~kg}$, after premature onset of labour at 34 weeks' gestation. The pregnancy had been otherwise normal and the mother's health had always been good. Progress was satisfactory and when discharged at 3 weeks of age she weighed $2.38 \mathrm{~kg}$. 6 days later, however, she was readmitted having apnoeic attacks and looking very ill. Lumbar puncture yielded purulent CSF which contained numerous Gram-positive cocci identified on culture as Strep. pneumoniae. Ampicillin (600 mg/kg per day) was given intravenously, penicillin (400,000 IU/kg per day) intramuscularly, hydrocortisone $(90 \mathrm{mg} / \mathrm{kg}$ per day) intramuscularly, and dexamethasone ( $3 \mathrm{mg} / \mathrm{kg}$ per day) intravenously. Intrathecal ampicillin $(25 \mathrm{mg}$ ) was given on the day of diagnosis and again 6 days later. Hydrocortisone $(25 \mathrm{mg})$ was also given intrathecally four times in the first 6 days. The steroids were discontinued after 8 days.

Initially the infant was unresponsive, with generalized hypotonia and intermittent myoclonic convulsions which were controlled with phenobarbitone. Nutrition was maintained by oral and intravenous feeding. Her condition remained unchanged for 12 days after which there was a gradual return of spontaneous movements. CSF was sterile after the second day of treatment and there was a reduction in the number of white cells, though the protein concentration remained high and the sugar level low (Table). After 20 days of treatment the head circumference was found to be rapidly increasing and therefore she was transferred to the neurosurgical unit at The Hospital for Sick Children, Great Ormond Street, London.

On admission the antibiotics were stopped, and a lumbar air-encephalogram showed gross hydrocephalus due to basal cistern block. CSF showed a rise in the total white cell count from $50 / \mathrm{mm}^{3}$ ( $98 \%$ polymorphs) to $675 / \mathrm{mm}^{3}$ (86\% polymorphs, $14 \%$ mononuclears). The protein concentration remained raised and the sugar level was still low, but the culture was sterile (Table). A further specimen of CSF was examined 4 days later when it was noted that the mononuclear cells had risen to $84 \%$ of 345 cells. Because of the continuing low sugar level the possibility of tuberculous meningitis was considered. Acid-alcohol fast bacilli were found using fluorescent microscopy and $M$. tuberculosis was subsequently grown in culture, the organism being sensitive to the drugs used in treatment.

Treatment was started using streptomycin $(25 \mathrm{mg} / \mathrm{kg}$ per day) intramuscularly, isoniazid (15 mg/kg per day), rifampicin (20 mg/kg per day), and pyridoxine ( 5 $\mathrm{mg} /$ day) orally, and streptomycin ( $1 \mathrm{mg} / \mathrm{kg}$ per day) and hydrocortisone ( $1 \mathrm{mg} / \mathrm{kg}$ per day) intrathecally. After 10 days a Rickham reservoir was inserted into the right lateral ventricle for control of hydrocephalus and so that intraventricular drugs could be given. A total of 20 alternating intrathecal and intraventricular injections were given over a period of one month. There was a progressive fall in the CSF white cell count and protein concentration, with a rise in the sugar level. The head circumference continued to increase in spite of tapping the Rickham reservoir and an air ventriculogram showed further increase in the size of the lateral ventricles. A ventriculoatrial shunt was inserted 35 days after tuberculosis was diagnosed and is functioning well. An unusual feature also found was the rapid appearance of symmetrical calcification in the region of the sylvian fissures (Fig.).

Mantoux skin tests (1:1000 PPD) were negative at the time tuberculous meningitis was diagnosed, and again 8 weeks later.

At 4 months of age the infant remains severely retarded in intellectual and motor functions. Examination of all known contacts at home and in the hospital did not reveal the source of the tuberculous infection.

\section{Discussion}

Meningitis in the neonate is uncommon and has an exceptionally poor prognosis. The reported incidence is $0 \cdot 46 / 1000$ live births, excluding cases with congenital malformations of the CNS, and there is a fourfold increase in risk among premature and low birthweight infants (Overall, 1970). Gram-negative bacteria account for two-thirds of the wide variety of organisms causing meningitis in

TABLE

CSF results

\begin{tabular}{|c|c|c|c|c|}
\hline $\begin{array}{l}\text { Days after onset of } \\
\text { symptoms }\end{array}$ & White cell count $/ \mathrm{mm}^{3}$ & $\begin{array}{c}\text { Protein } \\
(\mathrm{mg} / 100 \mathrm{ml})\end{array}$ & $\begin{array}{c}\text { Glucose } \\
(\mathrm{mg} / 100 \mathrm{ml})\end{array}$ & Culture \\
\hline $\begin{array}{r}1 \\
2 \\
4 \\
7 \\
12 \\
16 \\
23 \\
\\
27 \\
60\end{array}$ & $\begin{array}{r}37,000 \\
30,000 \\
2400 \\
220 \\
100 \text { polymorphs } 98 \% \\
50 \text { polymorphs } 98 \% \\
675 \text { polymorphs } 86 \% \\
\text { mononuclears } 14 \% \\
345 \text { mononuclears } 84 \% \\
3\end{array}$ & $\begin{array}{l}800 \\
390 \\
280 \\
250 \\
160 \\
200 \\
550 \\
\\
800 \\
125\end{array}$ & $\begin{array}{c}\text { Not measured } \\
\text { Not measured } \\
\text { Not measured } \\
\text { Not measured } \\
20 \\
16 \\
26 \\
23 \\
42\end{array}$ & $\begin{array}{l}\text { Strep. pneumoniae } \\
\text { Strep. pneumoniae } \\
\text { Sterile } \\
\text { Sterile } \\
\text { Sterile } \\
\text { Sterile } \\
\text { Sterile } \\
\text { M. tuberculosis } \\
\text { Sterile }\end{array}$ \\
\hline
\end{tabular}

^Acid-alcohol fast bacilli seen using fluorescent microscopy. 


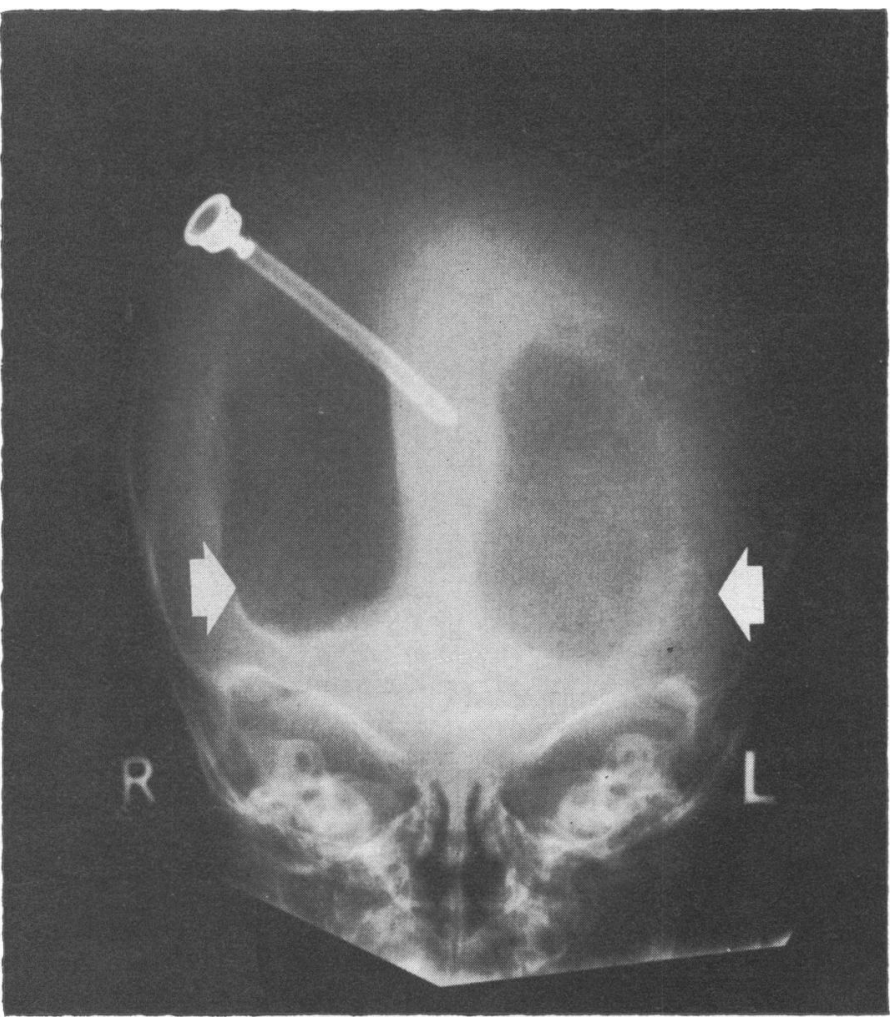

FIG.-X-ray showing hydrocephalus, Rickham reservoir, and bilateral intracranial calcification (arrowed).

the neonatal period (Fosson and Fine, 1968). Pneumococcal meningitis is less common at this age than in older infants and children. Tuberculous meningitis, especially in countries maintaining a good control over tuberculosis, is particularly rare in early infancy. Consequently, the combination of these two organisms causing a mixed infection is exceptional.

There have been only occasional reports of mixed simultaneous meningitis in previously published cases (Gaffney, 1940). Few of these involve tuberculous infection (Rosenthal, Linker, and Golomb, 1950), and it is more usual for a tuberculous infection either to precede or to follow the nontuberculous infection, so that clinically one is superimposed upon the other (Riley, 1955).

In view of the age at diagnosis, the possibility of a congenital tuberculous infection must be considered in this infant but appears unlikely as her mother was found to be free from active tuberculosis. The possibility of introducing the tuberculous infection during previous lumbar puncture procedures is remote.
Intracranial calcification is not uncommon in tuberculous meningitis but usually occurs in the basal cisterns. The calcification in the region of the sylvian fissures in our patient may be related to the mixed infection.

The use of intrathecal streptomycin and hydrocortisone in tuberculous meningitis is still controversial (British Medical Journal, 1971). In a controlled trial of this therapy, Freiman and Geefhuysen (1970) did not find conclusive evidence of its effectiveness. However, they also reported excellent recovery in a few severely affected patients and therefore we feel that its use in our patient was warranted.

Herweg et al. (1963) proposed that the term mixed simultaneous meningitis should only be used when different organisms are cultured from the initial CSF. In our patient the large number of pneumococci in the initial CSF was sufficient to account for the illness, and tubercle bacilli were not looked for. In retrospect, however, the persistently low CSF sugar and raised protein were suspicious and the case illustrates the importance of searching 
for tubercle bacilli even when tuberculous meningitis is only remotely suspected. As tuberculosis becomes less common, atypical cases are more likely to be missed unless a high index of suspicion is maintained.

\section{Summary}

A case of mixed meningitis in a young infant involving Strep. pneumoniae and $M$. tuberculosis is reported that emphasizes the diagnostic difficulties and the importance of searching for tubercle bacilli at the slightest suspicion.

We are grateful to Mr. K. Till and Dr. W. C. Marshall for permission to report this case.

\section{REFERENCES}

British Medical fournal (1971). Leader. Tuberculous meningitis in children, 1,1 .

Fosson, A. R., and Fine, R. N. (1968). Neonatal meningitis. Presentation and discussion of 21 cases. Clinical Pediatrics, 7, 404.

Freiman, I., and Geefhuysen, J. (1970). Evaluation of intrathecal therapy with streptomycin and hydrocortisone in tuberculous meningitis. Fournal of Pediatrics, 76, 895.

Gaffney, J. C. (1940). Mixed infection of the meninges with $H$. influenzae and pneumococcus. British Medical fournal, 1, 346.

Herweg, J. C., Middelkamp, J. N., and Hartmann, A. F. (1963). Simultaneous mixed bacterial meningitis in children. fournal of Pediatrics, 63, 76.

Overall, J. C. (1970). Neonatal bacterial meningitis. Analysis of predisposing factors and outcome compared with matched control subjects. Fournal of Pediatrics, 76, 499.

Riley, E. A. (1955). Combined pneumococcal and tuberculous meningitis. American Review of Tuberculosis, 71, 584.

Rosenthal, I. M., Linker, M. H., and Golomb, J. (1950). Tuberculous meningitis complicated by pyogenic meningitis caused by Streptococcus faecalis. American Review of Tuberculosis, 62, 441.

\section{R. J. LEVINSKY ${ }^{\star}$ and ANDREW WILKINSON†}

The Hospital for Sick Children, Great Ormond Street, London.

^Present address: Children's Hospital, Philadelphia, Pa., U.S.A. +Correspondence to Dr. A. Wilkinson, Children's Hospital, Winchester Road, Southampton SO9 4WR.

\section{Diazepam for fenfluramine intoxication}

Fenfluramine (Ponderax) is used increasingly as an adjunct to a low calorie diet in the treatment of obesity. There are an increasing number of reports of both children and adults who have suffered fenfluramine poisoning (Riley et al., 1969). At least 5 have been fatal (Fleisher and Campbell, 1969; Gold et al., 1969). Signs and symptoms shown by these patients were agitation and slight tremor, particularly of the lower jaw, with dilated pupils and tachycardia. Those with more severe poisoning have had abnormal eye movements, marked tremor, convulsions, unconsciousness, facial flushing, and hyperpyrexia, and cardiac and respiratory depression leading to cardiac arrhythmias and death.

We report 2 children who recovered from severe fenfluramine poisoning as judged by their clinical state and blood levels. Their treatment included the use of large doses of parenteral diazepam.

\section{Case reports}

Case 1. At about 5 p.m. this normally healthy 31-year-old girl was found by her mother in the garden acting oddly. She could not walk properly and her eyes 'looked funny'. Shortly after this her mother discovered that her fenfluramine tablets $(20 \mathrm{mg}$ each) had disappeared. 56 tablets were missing which, if all had been consumed, would have corresponded to a dose of $\mathbf{7 0}$ $\mathrm{mg} / \mathrm{kg}$ body weight. She was admitted to this hospital at 6.20 p.m. at which time she was restless, flushed, and her pupils were widely dilated but responsive to light. Her heart rate was 150/min and her systolic blood pressure was $140 \mathrm{mmHg}$.

She was given $5 \mathrm{mg}$ diazepam intramuscularly and vomiting was induced with $20 \mathrm{ml}$ of syrup of ipecac (BPC). The vomitus was copious and contained white matter but no complete tablets were found. Over the next hour she deteriorated, becoming increasingly restless with semivoluntary movements. She was flushed and was sweating profusely. She lay in opisthotonus, her limbs were stiff, and she was semiconscious. Her pupils were widely dilated and no longer responded to light. There was a coarse nystagmus and occasionally her eyes rolled upwards. Tachycardia increased to 190 to $200 / \mathrm{min}$, respirations were shallow, rapid, and irregular, and blood pressure remained raised. Throughout this time her temperature remained normal.

Intravenous fluids were given and repeated slow intravenous injections of diazepam, $5 \mathrm{mg}$ at a time, were administered to control her agitation and muscular spasms.

At 8.30 p.m., after a total of $35 \mathrm{mg}$ diazepam, she was asleep but her limbs were stiff. Respirations continued to be irregular and rapid, but tachycardia subsided.

At 9.15 p.m. she awoke and it was immediately apparent that her condition had improved. Her muscle tone and movements were normal. She remained awake and restless throughout the night and was therefore given two further doses of diazepam. Though her pupils remained dilated for about 24 hours the nystagmus ceased.

Over the following 48 hours she was drowsy but her general condition gradually improved. She had some difficulty in micturition, passing large quantities of urine infrequently. She was discharged on the third day having made a full recovery.

Case 2. A boy, aged 2 years 11 months, had been seen previously in outpatients because of behavioural 